\title{
Effect of diosgenin, a steroidal sapogenin, on the rat skeletal system
}

\author{
Joanna Folwarczna1, Maria Zych², Barbara Nowińska1, Maria Pytlik', Magdalena Bialik', \\ Anna Jagusiak', Maria Lipecka-Karcz¹ and Michał Matysiak
}

1Department of Pharmacology, School of Pharmacy with the Division of Laboratory Medicine, Medical University of Silesia, Katowice, Poland; 2Department of Pharmacognosy and Phytochemistry, School of Pharmacy with the Division of Laboratory Medicine, Medical University of

Silesia, Katowice, Poland

Diosgenin is a steroidal sapogenin present in fenugreek and Dioscorea spp. as glycosides (saponins). Diosgenin has already been reported to inhibit osteoclastogenesis and to stimulate osteogenic activity of osteoblastic cells in vitro, and to exert some antiosteoporotic effects in rats in vivo. The aim of the present study was to investigate the effects of diosgenin administration on the skeletal system of rats with normal estrogen level and with estrogen deficiency induced by bilateral ovariectomy. The experiments were carried out on 3-month-old nonovariectomized and ovariectomized Wistar rats, divided into control rats and rats receiving diosgenin $(50 \mathrm{mg} /$ kg p.o. daily) for 4 weeks. Serum bone turnover markers, bone mass and mineralization, histomorphometric parameters and mechanical properties were studied. Diosgenin improved some investigated parameters in both non-ovariectomized and ovariectomized rats, in which estrogen deficiency induced osteoporotic changes. Diosgenin increased compact bone formation and probably inhibited cancellous bone resorption, which led to improvement of mechanical properties of compact and cancellous bone. In conclusion, this in vivo study demonstrated that diosgenin may be one of sparse compounds increasing bone formation.

Key words: diosgenin, skeletal system, osteoporosis, estrogen deficiency, rats

Received: 15 July, 2015; revised: 30 November, 2015; accepted: 28 February, 2016; available on-line: 26 April, 2016

\section{INTRODUCTION}

Prevention and treatment of osteoporosis become more and more important, since the prevalence of osteoporosis increases due to population aging. In the treatment of osteoporosis, drugs inhibiting bone resorption or inducing bone formation are used; the majority of patients are treated with antiresorptive drugs (mainly bisphosphonates), whereas bone anabolic therapies (parathyroid hormone, strontium ranelate) are much less common (Rachner et al., 2011; Tella \& Gallagher, 2014). There is an interest in natural compounds present in dietary and medicinal plants that could be useful in the prevention and treatment of osteoporosis.

Diosgenin is a steroidal sapogenin of fenugreek (Trigonella foenum-graecum), different yams (Dioscorea spp., including $D$. villosa, D. spongiosa, D. esculenta, D. zingiberensis, D. opposita) and some other edible or medicinal plants, where it is present as glycosides (saponins) (Raju \& Mehta, 2009; Patel et al., 2012; Chiang \& Pan, 2013; Sato et al., 2014; Zhang et al., 2014b). Various health-promoting activities have been demonstrated for diosgenin, including anti-diabetic, anti-hyperlipidemic, cancer-chemopreventive, anti-inflammatory, immunomodulatory (Raju \& Mehta, 2009; Jung et al., 2010; Uemura et al., 2010; Chen et al., 2011; Patel et al., 2012; Rajput \& Mandal, 2012; Chiang \& Pan, 2013; Sato et al., 2014).

Diosgenin has been reported to exert some antiosteoporotic effect in preliminary studies on estrogen-deficient rats treated with its sustained delivery, as well as to inhibit osteoclastogenesis and to stimulate osteogenic activity of osteoblastic cells in vitro (Higdon et al., 2001; Scott et al., 2001; Shishodia \& Aggarwal, 2006; Alcantara et al., 2011). Very recently, a report on favorable effects of high-dose diosgenin in ovariectomized rats has been published (Zhang et al., 2014a). Moreover, diosgenin has been observed to counteract the development of some changes in rats with retinoic acid-induced osteoporosis (Zhao et al., 2015) and in OXYS rats with accelerated senescence (Tikhonova et al., 2015). Also, favorable effects of diosgenin-containing plant organs, their extracts or isolated saponins on the skeletal system have been demonstrated in experimental conditions (Yin et al., 2004; Yin et al., 2010; Chiang et al., 2011; Folwarczna et al., 2014a; Qu et al, 2014; Zhang et al., 2014b). The aim of the present study was to investigate the effects of diosgenin administration on the skeletal system of female rats with normal estrogen levels and with estrogen deficiency (bilaterally ovariectomized).

\section{MATERIALS AND METHODS}

Experiments were performed on mature (3-month-old) female Wistar rats obtained from the Center of Experimental Medicine, Medical University of Silesia, Katowice. The rats were fed a soy-free diet with decreased content of phenolic acids, ad libitum. The composition of the diet was presented in our previous reports (Folwarczna et al., 2013; 2015). The animals were switched from the standard laboratory diet (Labofeed B) to the experimental diet the day before the beginning of diosgenin administration. Both diets were produced by Wytwórnia Pasz "Morawski", Poland. The protocol for the experiments

e-mail: jfolwarczna@sum.edu.p

* Preliminary data were partially presented during 39th Annual Congress of the European Calcified Tissue Society, Stockholm 1923.05.2012. 
on animals was approved by the Local Ethics Commission, Katowice, Poland (permission no 33/2010).

Chemicals and drugs used: diosgenin (Sigma-Aldrich) at a dose of $50 \mathrm{mg} / \mathrm{kg}$ p.o. daily for 4 weeks, ketamine Bioketan (Vetoquinol Biowet), xylazine - Xylapan (Vetoquinol Biowet).

The animals were divided into 4 groups $(\mathrm{n}=8-10)$ :

I. Non-ovariectomized control rats,

II. Non-ovariectomized rats receiving diosgenin (50 $\mathrm{mg} / \mathrm{kg}$ p.o. daily),

III. Ovariectomized control rats,

IV. Ovariectomized rats receiving diosgenin $(50 \mathrm{mg} /$ kg p.o. daily).

Bilateral ovariectomy was performed 7-8 days before the start of diosgenin administration, under intraperitoneal ketamine-xylazine anesthesia. Diosgenin was administered once daily for 4 weeks, by a stomach tube (p.o.). Control rats were given the vehicle - tap water at the same volume of $2 \mathrm{ml} / \mathrm{kg}$ p.o. Moreover, to mark the calcification front, the animals were administered tetracycline hydrochloride $(20 \mathrm{mg} / \mathrm{kg}$ i.p.) twice: one day before the start of diosgenin or vehicle administration, and after 4 weeks.

The next day after the last diosgenin or vehicle administration, after overnight fasting, the animals were anesthetized with ketamine and xylazine, and sacrificed by cardiac exsanguination. The tibias, femurs and L-4 vertebra, as well as estrogen-dependent organs (uterus and thymus) were isolated. The length and diameter in the mid-length of left femur were measured. The left femur, L-4 vertebra, uterus and thymus were weighed. The left femurs and tibias, and proximal part of the right femurs were kept below $-20^{\circ} \mathrm{C}$ (wrapped in gauze soaked in $0.9 \% \mathrm{NaCl}$ solution) until the mechanical tests were performed on thawed bones (Turner \& Burr, 1993).

Biochemical studies. Serum concentrations of osteocalcin and type I collagen fragments released from bone during bone resorption were studied using enzyme immunoassays (Rat-MID Osteocalcin EIA and RatLaps EIA, respectively, Immunodiagnostic Systems Ltd). Serum estradiol concentrations were determined by an ELISA method (Mouse/Rat Estradiol ELISA, Calbiotech, Inc.). Moreover, serum levels of calcium were assayed colorimetrically (Pointe Scientific, Inc., reagent set).

Bone mineralization studies. To determine the mass of bone mineral, the bones were mineralized (ashed) at $640^{\circ} \mathrm{C}$ for $48 \mathrm{~h}$ in a muffle furnace and weighed. The ratio of bone mineral mass to bone mass was calculated and treated as a substitute for bone mineral density measurements. Calcium and phosphorus content in the mineralized bones were assayed spectrophotometrically, using kits manufactured by Pointe Scientific, Inc., as previously described (Folwarczna et al., 2013).

Histomorphometric studies. The specimens for histomorphometric measurements were prepared from the right tibias and femurs, as previously described (Folwarczna et al., 2004; 2013). The measurements were performed using Optiphot-2 microscope (Nikon) equipped with an RGB camera (Cohu) and connected to a personal computer, using Lucia G 4.51 software (Laboratory Imaging), with final magnifications of 200 and 500 times, or using Axio Imager.A1 microscope (Zeiss), Olympus DP 71 camera and OsteoMeasure XP v1.3.0.1 (OsteoMetrics) software (final magnification 70 times).

In transverse cross-sections made from the tibial diaphysis close to the point where the fibula grows into it, the area of the transverse cross-section of the cortical bone, the area of the transverse cross-section of the marrow cavity, the endosteal osteoid width, as well as the periosteal and endosteal transverse growth of the tibia were determined. The width of trabeculae in the distal epiphysis and metaphysis of the femur were measured in the longitudinal preparations.

Table 1. Effects of diosgenin ( $50 \mathrm{mg} / \mathrm{kg}$ p.o. daily for 4 weeks) on the body mass gain, mass of estrogen-dependent organs and serum biochemical parameters in non-ovariectomized and ovariectomized rats

\begin{tabular}{|c|c|c|c|c|c|c|c|}
\hline \multirow{3}{*}{ Parameter/Group } & \multicolumn{2}{|c|}{ Non-ovariectomized rats } & \multicolumn{2}{|c|}{ Ovariectomized rats } & \multicolumn{3}{|c|}{ Two-way ANOVA } \\
\hline & \multirow{2}{*}{ Control } & \multirow{2}{*}{ Diosgenin } & \multirow{2}{*}{ Control } & \multirow{2}{*}{ Diosgenin } & \multicolumn{2}{|c|}{ Main effects } & \multirow{2}{*}{ Interaction } \\
\hline & & & & & Ovariectomy & Diosgenin & \\
\hline $\begin{array}{l}\text { Body mass at the start } \\
\text { of diosgenin administra- } \\
\text { tion [g] }\end{array}$ & $235.6 \pm 3.3$ & $235.9 \pm 5.0$ & $226.8 \pm 4.7$ & $229.4 \pm 3.4$ & NS & NS & NS \\
\hline $\begin{array}{l}\text { Body mass gain } \\
\text { after } 4 \text { weeks [g] }\end{array}$ & $21.3 \pm 2.5$ & $14.2 \pm 3.7$ & $33.5 \pm 3.8^{*}$ & $31.5 \pm 3.4^{*}$ & $p<0.001$ & NS & NS \\
\hline Estradiol [pg/ml] & $24.57 \pm 2.48$ & $18.61 \pm 1.71$ & $16.82 \pm 2.12^{*}$ & $17.94 \pm 0.63^{*}$ & $p<0.05$ & NS & NS \\
\hline Uterus mass [g] & $0.385 \pm 0.045$ & $0.487 \pm 0.065$ & $0.080 \pm 0.004^{* * *}$ & $0.081 \pm 0.002^{* * *}$ & $p<0.001$ & NS & NS \\
\hline Thymus mass [g] & $0.305 \pm 0.014$ & $0.295 \pm 0.014$ & $0.536 \pm 0.034^{* * *}$ & $0.489 \pm 0.036^{* * *}$ & $p<0.001$ & NS & NS \\
\hline Osteocalcin [ng/ml] & $195.2 \pm 18.6$ & $171.3 \pm 12.0$ & $327.1 \pm 27.5^{* *}$ & $329.1 \pm 38.8^{* *}$ & $p<0.001$ & NS & NS \\
\hline RatLaps [ng/ml] & $24.23 \pm 2.64$ & $22.90 \pm 1.98$ & $42.21 \pm 2.73^{* * *}$ & $40.71 \pm 2.72^{* * *}$ & $p<0.001$ & NS & NS \\
\hline Calcium [mg/100 ml] & $10.01 \pm 0.21$ & $10.17 \pm 0.16$ & $9.65 \pm 0.18$ & $9.49 \pm 0.24$ & $p<0.05$ & NS & NS \\
\hline
\end{tabular}

Results are presented as means \pm SEM. One-way ANOVA followed by Duncan's test, or, when appropriate, Kruskal-Wallis ANOVA followed by MannWhitney $U$ test, were used for evaluation of the significance of the results. ${ }^{*} p<0.05,{ }^{* *} p<0.01$, ${ }^{* * *} p<0.001$, significantly different from non-ovariectomized control rats. NS, not significant. 
Bone mechanical properties studies. Mechanical properties of bones were studied using an Instron 3342 $500 \mathrm{~N}$ apparatus and Bluehill 2 version 2.14 software (Instron).

Mechanical properties of the left femoral diaphysis (compact bone) and tibial metaphysis (cancellous bone) were assessed using bending tests with three-point loading, as previously described (Turner \& Burr, 1993; Stürmer et al., 2006; Folwarczna et al., 2013). The load was applied perpendicularly to the long axis of the femur in the mid-length of the bone, or to the proximal tibial metaphysis ( $3 \mathrm{~mm}$ from the proximal edge of the bone deprived of the proximal epiphysis), also perpendicularly to the long axis of the bone. Maximum load and displacement, energy and stress for the maximum load were assessed. The same parameters were determined for the yield point $(0.05 \%$ offset $)$ and fracture point. Young's modulus was also determined. For computation of the moment of inertia, necessary to calculate the intrinsic parameters (stress and Young's modulus), it was assumed that the femoral diaphysis was an elliptical pipe, and the tibial metaphysis - a circular beam (Folwarczna et al., 2013).

The femoral neck strength was studied using the compression test (Folwarczna et al., 2013). The load was applied to the head of the right femur along the long axis of the femur and the maximum load was measured.

Statistical analysis. Results are presented as means \pm SEM. One-way ANOVA followed by Duncan's test or, in case of the lack of normality or of homogeneity of variance, Kruskal-Wallis ANOVA followed by MannWhitney $U$ test, were used to evaluate the statistical significance of the results. Moreover, two-way ANOVA was also conducted in order to evaluate whether the effect of diosgenin depended on estrogen status. Interaction between the main effects of estrogen deficiency and diosgenin treatment was assessed.

\section{RESULTS}

\section{Effects of diosgenin on the body mass gain, mass of estrogen-dependent organs and serum biochemical parameters}

The ovariectomized rats were estrogen-deficient, as demonstrated by significant decrease in the serum estradiol level and uterine mass, as well as the increase in the thymus mass and body mass gain (Table 1). Administration of diosgenin ( $50 \mathrm{mg} / \mathrm{kg}$ p.o. daily for 4 weeks) did not affect the body mass gain, serum estradiol level and the mass of estrogen-dependent organs, both in nonovariectomized and ovariectomized rats. After administration of diosgenin, no effects on levels of biochemical markers of bone formation (osteocalcin) and bone resorption (RatLaps) were observed, both in non-ovariectomized and ovariectomized rats, in which they were significantly increased in relation to the non-ovariectomized

Table 2. Effects of diosgenin ( $50 \mathrm{mg} / \mathrm{kg}$ p.o. daily for 4 weeks) on bone mass, mineralization and macrometric parameters in nonovariectomized and ovariectomized rats

\begin{tabular}{|c|c|c|c|c|c|c|c|c|}
\hline \multirow{3}{*}{ Parameter/Group } & & \multicolumn{2}{|c|}{ Non-ovariectomized rats } & \multicolumn{2}{|c|}{ Ovariectomized rats } & \multicolumn{3}{|c|}{ Two-way ANOVA } \\
\hline & & \multirow{2}{*}{ Control } & \multirow{2}{*}{ Diosgenin } & \multirow{2}{*}{ Control } & \multirow{2}{*}{ Diosgenin } & \multicolumn{2}{|c|}{ Main effects } & \multirow{2}{*}{$\begin{array}{c}\text { Interac- } \\
\text { tion }\end{array}$} \\
\hline & & & & & & $\begin{array}{l}\text { Ovariecto- } \\
\text { my }\end{array}$ & $\begin{array}{c}\text { Diosge- } \\
\text { nin }\end{array}$ & \\
\hline \multirow{2}{*}{ Bone mass [g] } & Femur & $0.710 \pm 0.014$ & $0.715 \pm 0.017$ & $0.709 \pm 0.019$ & $0.728 \pm 0.012$ & NS & NS & NS \\
\hline & L-4 vertebra & $0.200 \pm 0.004$ & $0.200 \pm 0.006$ & $0.203 \pm 0.009$ & $0.207 \pm 0.007$ & NS & NS & NS \\
\hline \multirow{2}{*}{$\begin{array}{l}\text { Bone mineral } \\
\text { mass }[\mathrm{g}]\end{array}$} & Femur & $0.314 \pm 0.004$ & $0.320 \pm 0.007$ & $0.290 \pm 0.007^{*}$ & $0.305 \pm 0.004$ & $p<0.01$ & NS & NS \\
\hline & L-4 vertebra & $0.083 \pm 0.001$ & $0.083 \pm 0.002$ & $0.075 \pm 0.003^{*}$ & $0.080 \pm 0.002$ & $p<0.05$ & NS & NS \\
\hline \multirow{2}{*}{$\begin{array}{l}\text { Mass of bone } \\
\text { mineral/bone } \\
\text { mass ratio }\end{array}$} & Femur & $0.443 \pm 0.006$ & $0.448 \pm 0.003$ & $0.410 \pm 0.004^{* * *}$ & $0.419 \pm 0.004^{* *}$ & $p<0.001$ & NS & NS \\
\hline & L-4 vertebra & $0.418 \pm 0.007$ & $0.414 \pm 0.005$ & $0.371 \pm 0.010^{* * *}$ & $0.387 \pm 0.009^{*}$ & $p<0.001$ & NS & NS \\
\hline \multirow{2}{*}{$\begin{array}{l}\text { Calcium content } \\
\text { [g/g of bone mi- } \\
\text { neral] }\end{array}$} & Femur & $0.360 \pm 0.004$ & $0.363 \pm 0.004$ & $0.358 \pm 0.006$ & $0.362 \pm 0.004$ & NS & NS & NS \\
\hline & L-4 vertebra & $0.362 \pm 0.007$ & $0.360 \pm 0.005$ & $0.339 \pm 0.003^{*}$ & $0.353 \pm 0.003 \bullet$ & $p<0.01$ & NS & NS \\
\hline \multirow{2}{*}{$\begin{array}{l}\text { Phosphorus con- } \\
\text { tent [g/g of bone } \\
\text { mineral] }\end{array}$} & Femur & $0.162 \pm 0.002$ & $0.165 \pm 0.002$ & $0.162 \pm 0.002$ & $0.164 \pm 0.001$ & NS & NS & NS \\
\hline & L-4 vertebra & $0.176 \pm 0.003$ & $0.174 \pm 0.002$ & $0.168 \pm 0.002$ & $0.176 \pm 0.001$ & NS & NS & NS \\
\hline \multicolumn{2}{|l|}{ Femur length [mm] } & $34.5 \pm 0.4$ & $34.0 \pm 0.4$ & $33.9 \pm 0.6$ & $34.4 \pm 0.4$ & NS & NS & NS \\
\hline \multicolumn{2}{|c|}{ Femur diameter [mm] } & $2.99 \pm 0.03$ & $3.10 \pm 0.05$ & $3.00 \pm 0.03$ & $3.06 \pm 0.03$ & NS & $p<0.05$ & NS \\
\hline
\end{tabular}

Results are presented as means \pm SEM. One-way ANOVA followed by Duncan's test, or, when appropriate, Kruskal-Wallis ANOVA followed by MannWhitney $U$ test, were used for evaluation of the significance of the results. ${ }^{*} p<0.05,{ }^{* *} p<0.01$, ${ }^{* * *} p<0.001$, significantly different from non-ovariectomized control rats. $\bullet p<0.05$, significantly different from ovariectomized control rats. NS, not significant. 
Table 3. Effects of diosgenin ( $50 \mathrm{mg} / \mathrm{kg}$ p.o. daily for 4 weeks) on bone histomorphometric parameters in non-ovariectomized and ovariectomized rats

\begin{tabular}{|c|c|c|c|c|c|c|c|c|}
\hline \multirow{3}{*}{ Parameter/Group } & & \multicolumn{2}{|c|}{ Non-ovariectomized rats } & \multicolumn{2}{|c|}{ Ovariectomized rats } & \multicolumn{3}{|c|}{ Two-way ANOVA } \\
\hline & & \multirow[b]{2}{*}{ Control } & \multirow[b]{2}{*}{ Diosgenin } & \multirow[b]{2}{*}{ Control } & \multirow[b]{2}{*}{ Diosgenin } & \multicolumn{2}{|c|}{ Main effects } & \multirow{2}{*}{$\begin{array}{l}\text { Interac- } \\
\text { tion }\end{array}$} \\
\hline & & & & & & $\begin{array}{l}\text { Ovariec- } \\
\text { tomy }\end{array}$ & $\begin{array}{l}\text { Diosge- } \\
\text { nin }\end{array}$ & \\
\hline \multirow{2}{*}{$\begin{array}{l}\text { Transverse growth of the } \\
\text { tibia }[\mu \mathrm{m}]\end{array}$} & $\begin{array}{l}\text { Perio- } \\
\text { steal }\end{array}$ & $41.72 \pm 2.20$ & $57.53 \pm 4.96^{*}$ & $47.57 \pm 1.59$ & $62.99 \pm 6.32^{* *}$ & NS & $p<0.001$ & NS \\
\hline & $\begin{array}{l}\text { Endo- } \\
\text { steal }\end{array}$ & $25.53 \pm 1.25$ & $28.17 \pm 2.61$ & $31.62 \pm 2.36$ & $33.94 \pm 2.88$ & $p<0.05$ & NS & NS \\
\hline \multicolumn{2}{|c|}{$\begin{array}{l}\text { Width of endosteal osteoid in the } \\
\text { tibia }[\mu \mathrm{m}]\end{array}$} & $10.80 \pm 0.17$ & $10.50 \pm 0.16$ & $11.56 \pm 0.10^{*}$ & $11.89 \pm 0.14^{* *}$ & $p<0.001$ & NS & $p<0.05$ \\
\hline \multicolumn{2}{|c|}{$\begin{array}{l}\text { Transverse cross-section area of the } \\
\text { cortical bone in the tibial diaphysis } \\
{\left[\mathrm{mm}^{2}\right]}\end{array}$} & $3.490 \pm 0.079$ & $3.754 \pm 0.059^{*}$ & $3.419 \pm 0.089$ & $3.745 \pm 0.083^{*}$ & NS & $p<0.001$ & NS \\
\hline \multicolumn{2}{|c|}{$\begin{array}{l}\text { Transverse cross-section area of the } \\
\text { tibial marrow cavity }\left[\mathrm{mm}^{2}\right]\end{array}$} & $0.870 \pm 0.058$ & $0.822 \pm 0.044$ & $0.840 \pm 0.030$ & $0.901 \pm 0.040$ & NS & NS & NS \\
\hline \multicolumn{2}{|c|}{$\begin{array}{l}\text { Transverse cross-section area of the } \\
\text { tibial marrow cavity / transverse cross- } \\
\text {-section area of the tibial diaphysis } \\
\text { ratio }\end{array}$} & $0.199 \pm 0.012$ & $0.179 \pm 0.008$ & $0.198 \pm 0.008$ & $0.194 \pm 0.009$ & NS & NS & NS \\
\hline \multirow{2}{*}{$\begin{array}{l}\text { Width of trabeculae in the } \\
\text { femur }[\mu \mathrm{m}]\end{array}$} & $\begin{array}{l}\text { Epiphy- } \\
\text { sis }\end{array}$ & $63.44 \pm 0.35$ & $65.16 \pm 0.40^{* *}$ & $60.68 \pm 0.50^{* * *}$ & $62.08 \pm 1.23$ & $p<0.001$ & $p<0.05$ & NS \\
\hline & $\begin{array}{l}\text { Meta- } \\
\text { physis }\end{array}$ & $45.22 \pm 0.24$ & $47.33 \pm 0.44^{* * *}$ & $42.59 \pm 0.41 * * *$ & $46.45 \pm 1.28 \bullet \bullet$ & $p<0.05$ & $p<0.001$ & NS \\
\hline
\end{tabular}

Results are presented as means \pm SEM. One-way ANOVA followed by Duncan's test, or, when appropriate, Kruskal-Wallis ANOVA followed by MannWhitney $U$ test, were used for evaluation of the significance of the results. ${ }^{*} p<0.05,{ }^{* *} p<0.01,{ }^{* *} p<0.001$, significantly different from non-ovariectomized control rats. $\bullet p<0.05, \bullet p<0.01$, significantly different from ovariectomized control rats. NS, not significant.

controls. There was also no diosgenin effect on the serum calcium concentration.

\section{Effects of diosgenin on bone mass, macrometric parameters and mineralization}

Administration of diosgenin did not significantly affect bone mass, bone mineral mass and mineralization (the ratio of bone mineral mass to bone mass), both in nonovariectomized and ovariectomized rats, although mass and mineral mass of the femur tended to increase ( $\mathrm{Ta}$ ble 2). Diosgenin increased the calcium content in the mineral of the vertebra in ovariectomized rats. The diameter of the femur increased in the diosgenin-treated rats (as shown in two-way ANOVA). It should be noted that estrogen deficiency decreased the mass of bone mineral and strongly reduced bone mineralization both in the femur and vertebra, and decreased calcium content in the vertebra mineral. There were no effects of estrogen deficiency on the femoral length and diameter.

\section{Effects of diosgenin on bone histomorphometric parameters}

Histomorphometric measurements in the ovariectomized control rats demonstrated a tendency to increase compact bone formation (there was a tendency to increase the transverse growth in the tibial diaphysis and a significant increase in the width of endosteal osteoid) and no effect on compact bone resorption (the transverse cross-section area of tibial marrow cavity and its ratio to the transverse cross-section area of the whole di- aphysis, Table 3). Administration of diosgenin increased the periosteal transverse growth of the tibia, both in non-ovariectomized and ovariectomized rats in relation to appropriate controls. Also, an increase in the area of the cortical bone in the transverse cross-sections of the tibial diaphysis was observed. Diosgenin did not affect the width of endosteal osteoid in the tibial diaphysis.

In cancellous bone of the femoral epiphysis and metaphysis, diosgenin increased the width of trabeculae in comparison with appropriate controls, regardless of the estrogen status. Those parameters were significantly decreased in the ovariectomized control rats, indicating increased bone resorption.

\section{Effects of diosgenin on bone mechanical properties}

In ovariectomized rats, diosgenin significantly increased the maximum load sustained by the tibial metaphysis and the energy accumulated to the fracture point in relation to the ovariectomized controls, slightly counteracting the effects of estrogen deficiency (Table 4), since in the ovariectomized control rats, Young's modulus, yield load and the load, stress and energy accumulated for both the points of maximum load and fracture, were significantly decreased in relation to the non-ovariectomized control rats. Diosgenin did not significantly affect the strength of the tibial metaphysis in non-ovariectomized rats in comparison to the non-ovariectomized control rats, except the increase in the yield load and stress. However, two-way ANOVA revealed significant diosgenin main effects (increasing) for the yield 
Table 4. Effects of diosgenin (50 mg/kg p.o. daily for 4 weeks) on mechanical properties of the tibial metaphysis in non-ovariectomized and ovariectomized rats

\begin{tabular}{|c|c|c|c|c|c|c|c|}
\hline \multirow{3}{*}{ Parameter/Group } & \multicolumn{2}{|c|}{ Non-ovariectomized rats } & \multicolumn{2}{|c|}{ Ovariectomized rats } & \multicolumn{3}{|c|}{ Two-way ANOVA } \\
\hline & \multirow{2}{*}{ Control } & \multirow{2}{*}{ Diosgenin } & \multirow{2}{*}{ Control } & \multirow{2}{*}{ Diosgenin } & \multicolumn{2}{|c|}{ Main effects } & \multirow{2}{*}{ Interaction } \\
\hline & & & & & Ovariectomy & Diosgenin & \\
\hline Young's modulus [MPa] & $2382 \pm 237$ & $2561 \pm 343$ & $1722 \pm 266^{*}$ & $1406 \pm 246^{* *}$ & $p<0.01$ & NS & NS \\
\hline Yield load (0.05\% offset) [N] & $44.1 \pm 2.7$ & $67.2 \pm 9.8^{*}$ & $35.3 \pm 3.1^{*}$ & $38.7 \pm 4.1$ & $p<0.01$ & $p<0.05$ & NS \\
\hline $\begin{array}{l}\text { Displacement for yield load } \\
\text { [mm] }\end{array}$ & $0.264 \pm 0.026$ & $0.395 \pm 0.059$ & $0.274 \pm 0.024$ & $0.350 \pm 0.070$ & NS & $p<0.05$ & NS \\
\hline Energy for yield load [mJ] & $5.49 \pm 0.77$ & $14.37 \pm 4.04$ & $4.90 \pm 0.89$ & $6.92 \pm 2.17$ & NS & $p<0.05$ & NS \\
\hline Stress for yield load [MPa] & $30.1 \pm 3.4$ & $45.2 \pm 7.0^{*}$ & $23.9 \pm 2.7$ & $23.0 \pm 2.4$ & $p<0.01$ & NS & NS \\
\hline Maximum load [N] & $101.9 \pm 5.5$ & $111.9 \pm 6.7$ & $64.6 \pm 2.5^{* * *}$ & $76.9 \pm 4.4^{* *} \bullet$ & $p<0.001$ & $p<0.05$ & NS \\
\hline $\begin{array}{l}\text { Displacement } \\
\text { for maximum load [mm] }\end{array}$ & $0.898 \pm 0.067$ & $0.837 \pm 0.062$ & $0.738 \pm 0.058$ & $0.905 \pm 0.043$ & NS & NS & NS \\
\hline $\begin{array}{l}\text { Energy } \\
\text { for maximum load [mJ] }\end{array}$ & $54.94 \pm 4.82$ & $52.51 \pm 6.01$ & $29.34 \pm 2.96^{* *}$ & $41.86 \pm 4.30$ & $p<0.001$ & NS & NS \\
\hline Maximum stress [MPa] & $69.2 \pm 7.2$ & $76.5 \pm 7.2$ & $43.6 \pm 3.4^{* *}$ & $46.2 \pm 4.0^{*}$ & $p<0.001$ & NS & NS \\
\hline Fracture load [N] & $77.8 \pm 5.6$ & $72.4 \pm 3.1$ & $43.2 \pm 1.9^{* * *}$ & $48.3 \pm 2.1^{* * *}$ & $p<0.001$ & NS & NS \\
\hline $\begin{array}{l}\text { Displacement } \\
\text { for fracture load [mm] }\end{array}$ & $1.175 \pm 0.055$ & $1.194 \pm 0.070$ & $1.197 \pm 0.058$ & $1.393 \pm 0.069$ & NS & NS & NS \\
\hline $\begin{array}{l}\text { Energy } \\
\text { for fracture load [mJ] }\end{array}$ & $79.57 \pm 4.71$ & $87.21 \pm 7.94$ & $54.26 \pm 2.32^{* *}$ & $73.16 \pm 5.44^{凶}$ & $p<0.01$ & $p<0.05$ & NS \\
\hline $\begin{array}{l}\text { Stress } \\
\text { for fracture load [MPa] }\end{array}$ & $52.5 \pm 5.8$ & $50.3 \pm 5.4$ & $29.4 \pm 2.6^{* * *}$ & $28.9 \pm 2.1^{* *}$ & $p<0.001$ & NS & NS \\
\hline
\end{tabular}

Results are presented as means \pm SEM. One-way ANOVA followed by Duncan's test, or, when appropriate, Kruskal-Wallis ANOVA followed by MannWhitney $U$ test, were used for evaluation of the significance of the results. ${ }^{*} p<0.05,{ }^{* *} p<0.01$, ${ }^{* * *} p<0.001$, significantly different from non-ovariectomized control rats. $\bullet p<0.05$, significantly different from ovariectomized control rats. NS, not significant

load, displacement and energy, as well as for the maximum load and the energy accumulated to the fracture point, indicating that the improvement of the mechanical properties in the tibia did not depend on the estrogen status.

In the femoral diaphysis, diosgenin slightly tended to increase the maximum load sustained by the bone, both in non-ovariectomized and ovariectomized rats (Table 5). Diosgenin significantly increased the load value registered at fracture point in non-ovariectomized rats. There was also a significant diosgenin main effect concerning the fracture load in two-way ANOVA (increasing). What is more, diosgenin counteracted the increase in the yield point displacement in ovariectomized rats. Diosgenin did not significantly affect the strength of the femoral neck, regardless of estrogen status. The mechanical parameters of the femoral neck and diaphysis (with the exception of the yield point displacement) were not affected by estrogen deficiency.

\section{DISCUSSION}

The first reports on the effects of diosgenin on the skeletal system in experimental conditions were published by Hidgon, Scott and coworkers in 2001. Dios- genin in sustained delivery from subcutaneous implants (for 33 days) was reported to exert some beneficial effects on histomorphometric parameters and mechanical strength of the femoral diaphysis in ovariectomized rats (Higdon et al., 2001; Scott et al., 2001). However, the small number of rats per experimental group $(n=4)$ and the lack of data on the daily dose of diosgenin released from the implant (containing $500 \mathrm{mg}$ of diosgenin) allow to treat those reports as preliminary observations. The studies on effects of diosgenin on osteoclastogenesis and osteoblast activity confirmed the possibility of its beneficial influence on the skeletal system (Shishodia \& Aggarwal, 2006; Alcantara et al., 2011).

There also exist several reports concerning favorable effects of glycosides of diosgenin, as well as their plant sources, on the skeletal system of ovariectomized rats (Yin et al., 2004; Chiang et al., 2011; Folwarczna et al., 2014a; Zhang et al., 2014b). However, their effects may differ from those of diosgenin. Plant extracts contain diosgenin mainly as glycosides (saponins); they also include other, various components (like flavonoids or alkaloids) which may exert their own effects on the skeletal system. For example, in studies performed parallelly to the study reported here, we observed that fenugreek seed ( $1 \%$ in the diet) tended to favorably affect the rat skeletal system, whereas at a higher dose (administered as an 
Table 5. Effects of diosgenin ( $50 \mathrm{mg} / \mathrm{kg}$ p.o. daily for 4 weeks) on mechanical properties of the femoral diaphysis and femoral neck in non-ovariectomized and ovariectomized rats

\begin{tabular}{|c|c|c|c|c|c|c|c|}
\hline \multirow{3}{*}{ Parameter/Group } & \multicolumn{2}{|c|}{ Non-ovariectomized rats } & \multicolumn{2}{|c|}{ Ovariectomized rats } & \multicolumn{3}{|c|}{ Two-way ANOVA } \\
\hline & \multirow[b]{2}{*}{ Control } & \multirow[b]{2}{*}{ Diosgenin } & \multirow[b]{2}{*}{ Control } & \multirow[b]{2}{*}{ Diosgenin } & \multicolumn{2}{|c|}{ Main effects } & \multirow{2}{*}{$\begin{array}{l}\text { Interac- } \\
\text { tion }\end{array}$} \\
\hline & & & & & $\begin{array}{l}\text { Ovariec- } \\
\text { tomy }\end{array}$ & Diosgenin & \\
\hline Young's modulus [MPa] & $8263 \pm 422$ & $8590 \pm 453$ & $7800 \pm 444$ & $8062 \pm 408$ & NS & NS & NS \\
\hline Yield load (0.05\% offset) [N] & $74.5 \pm 3.0$ & $79.1 \pm 4.2$ & $73.7 \pm 2.4$ & $75.3 \pm 2.5$ & NS & NS & NS \\
\hline Displacement for yield load [mm] & $0.242 \pm 0.010$ & $0.239 \pm 0.008$ & $0.299 \pm 0.013^{* *}$ & $0.260 \pm 0.014 \bullet$ & $p<0.01$ & NS & NS \\
\hline Energy for yield load [mJ] & $8.84 \pm 0.60$ & $9.04 \pm 0.73$ & $9.60 \pm 0.52$ & $8.89 \pm 0.46$ & NS & NS & NS \\
\hline Stress for yield load [MPa] & $115.9 \pm 4.8$ & $115.8 \pm 5.9$ & $117.4 \pm 5.4$ & $115.3 \pm 4.4$ & NS & NS & NS \\
\hline Maximum load $[\mathrm{N}]$ & $111.4 \pm 3.0$ & $118.5 \pm 4.3$ & $108.3 \pm 3.1$ & $113.8 \pm 3.5$ & NS & NS & NS \\
\hline $\begin{array}{l}\text { Displacement } \\
\text { for maximum load [mm] }\end{array}$ & $0.563 \pm 0.022$ & $0.528 \pm 0.024$ & $0.590 \pm 0.021$ & $0.576 \pm 0.028$ & NS & NS & NS \\
\hline $\begin{array}{l}\text { Energy } \\
\text { for maximum load [mJ] }\end{array}$ & $39.61 \pm 2.16$ & $38.16 \pm 2.48$ & $36.21 \pm 1.75$ & $39.71 \pm 3.30$ & NS & NS & NS \\
\hline Maximum stress [MPa] & $173.7 \pm 5.7$ & $173.5 \pm 5.6$ & $175.3 \pm 9.2$ & $174.2 \pm 6.1$ & NS & NS & NS \\
\hline Fracture load $[\mathrm{N}]$ & $98.9 \pm 4.2$ & $115.8 \pm 4.0^{*}$ & $103.0 \pm 4.1$ & $108.4 \pm 4.1$ & NS & $p<0.05$ & NS \\
\hline $\begin{array}{l}\text { Displacement } \\
\text { for fracture load [mm] }\end{array}$ & $0.682 \pm 0.049$ & $0.568 \pm 0.044$ & $0.633 \pm 0.027$ & $0.685 \pm 0.060$ & NS & NS & NS \\
\hline $\begin{array}{l}\text { Energy } \\
\text { for fracture load [mJ] }\end{array}$ & $51.87 \pm 5.13$ & $43.13 \pm 5.57$ & $40.87 \pm 2.58$ & $51.59 \pm 5.45$ & NS & NS & NS \\
\hline $\begin{array}{l}\text { Stress } \\
\text { for fracture load [MPa] }\end{array}$ & $153.6 \pm 6.0$ & $169.6 \pm 5.7$ & $165.3 \pm 9.0$ & $166.1 \pm 7.2$ & NS & NS & NS \\
\hline Femoral neck - maximum load [N] & $88.3 \pm 3.1$ & $88.6 \pm 5.3$ & $79.9 \pm 2.2$ & $89.0 \pm 8.3$ & NS & NS & NS \\
\hline
\end{tabular}

Results are presented as means \pm SEM. One-way ANOVA followed by Duncan's test, or, when appropriate, Kruskal-Wallis ANOVA followed by MannWhitney $U$ test, were used for evaluation of the significance of the results. ${ }^{*} p<0.05,{ }^{* *} p<0.01$, significantly different from non-ovariectomized control rats. $\bullet p<0.05$, significantly different from ovariectomized control rats. NS, not significant.

extract) it induced some unfavorable effects in estrogendeficient rats (Folwarczna et al., 2014a), to which trigonelline could contribute (Folwarczna et al., 2014b). Effects of diosgenyl saponins may also differ from those of diosgenin, due to, among others, different bioavailability. In fact, the bioavailability of dioscin seemed to be better than that of diosgenin (Manda et al., 2013).

The diosgenin dose, used in the present study (50 $\mathrm{mg} / \mathrm{kg}$ p.o. daily), was rather high, however diosgenin is poorly absorbed (Cayen \& Dvornik, 1979). The low oral bioavailability of diosgenin (about $4.3 \%$ in rats) (Okawara et al., 2013) is probably due to the fact that it is a substrate for P-glycoprotein (Manda et al., 2013). Taking the above into account, the oral dose used was of similar range to the intraperitoneal dose effective in hyperglycemic rats (Sato et al., 2014). The duration of treatment (4 weeks) was long enough to evaluate the skeletal effects of different drugs and natural compounds in rats in our previous studies (Folwarczna et al., 2004; 2013; 2015).

Results of the present study indicate that diosgenin at a dose of $50 \mathrm{mg} / \mathrm{kg}$ p.o. daily, administered for 4 weeks, favorably affected the female rat skeletal system, slightly improving bone structure and strength. We investigated diosgenin effects in rats with normal estrogen levels and in estrogen-deficient (bilaterally ovariectomized) rats, in which characteristic osteoporotic changes developed: increase in bone resorption and formation, disordered mineralization and worsened mechanical properties of cancellous bone (tibial metaphysis) (Folwarczna et al., 2014a; 2014b).

Administration of diosgenin counteracted some of the skeletal changes developing due to estrogen deficiency in ovariectomized rats. Although diosgenin did not improve bone mineralization (the ratio of mass of bone mineral to bone mass), it alleviated the effect of estrogen deficiency on the calcium content in the vertebra mineral and on cancellous bone structure (width of femoral trabeculae), which induced improvement in the mechanical properties of the tibial metaphysis. Those effects might have resulted from the decreased cancellous bone resorption and/or increased bone formation. Diosgenin not only did not counteract the increased compact bone formation in ovariectomized rats, but further intensified it. The minor increase in the compact bone growth (periosteal transverse growth of the tibial diaphysis and femoral diaphysis diameter) probably led to slight improvement in strength of the femoral diaphysis. In fact, diosgenin affected rather the extrinsic, i.e. depending on the bone size, mechanical parameters (like the values of 
load and of energy absorbed), than the intrinsic parameters (stress, Young's modulus).

Interestingly, the same effects or tendencies were demonstrated for the skeletal parameters of normal, non-ovariectomized, female rats. Two-way ANOVA revealed that diosgenin exerted its effects regardless of the estrogen status (significant diosgenin main effects and the lack of interactions between the main effects of diosgenin and ovariectomy).

The decreasing of bone resorption by diosgenin is consistent with its effects on osteoclast formation in vitro. It was demonstrated that diosgenin inhibited receptor activator of nuclear factor $x \mathrm{~B}$ ligand (RANKL)-stimulated osteoclastogenesis in the culture of Raw 264.7 (mouse macrophage) cells (Shishodia \& Aggarwal, 2006). Moreover, the long-term (12-week) treatment with diosgenin at a high dose of $96 \mathrm{mg} / \mathrm{kg}$ p.o. daily in 6-month-old ovariectomized rats counteracted the effects of estrogendeficiency on bone mineral density and trabecular bone histomorphometry, decreasing the RANKL/osteoprotegerin ratio (assessed by immunohistochemistry and in situ hybridization; Zhang et al., 2014a).

One may speculate that inhibition of bone resorption by diosgenin may be connected with its ability to induce activation of high conductance $\mathrm{Ca}^{2+}$-activated $\mathrm{K}^{+}(\mathrm{BK})$ channels, through which it exerts the vasodilatory action (Au et al., 2004; Dias et al., 2007). Since targeted deletion of $\mathrm{BK}$ channel resulted in increased cathepsin $\mathrm{K}$ release in osteoclasts and development of osteopenia in juvenile mice (Sausbier et al., 2011), it is possible that diosgenin, by activation of BK channels, may decrease cathepsin $\mathrm{K}$ release and in consequence inhibit bone resorption.

Also, the increase in bone formation observed in the present study is consistent with the previous in vitro studies (Yen et al., 2005; Alcantara et al., 2011). Low concentrations of diosgenin increased proliferation and stimulated the synthesis and secretion of type 1 collagen, alkaline phosphatase and osteopontin in murine osteoblastic MC3T3-E1 cells, although at a higher concentration $(10 \mu \mathrm{M})$ diosgenin was cytotoxic (Alcantara et al., 2011). Consistently, Zhang et al. (2014a) demonstrated the decrease in bone formation indices after a larger diosgenin dose in vivo. It is possible that diosgenin may stimulate bone formation through activation of angiogenesis in bone. In MC3T3-E1 cells, diosgenin upregulated vascular endothelial growth factor-A, playing an important role during fracture repair and bone formation, usually accompanied by the formation of new capillary vessels (Yen et al., 2005). However, the diosgenin effects on bone resorption and formation were not strong enough to affect the serum levels of bone turnover markers in the present in vivo study.

Diosgenin has been widely used in the pharmaceutical industry as a precursor in the synthesis of steroids, including sex hormones. It is believed that diosgenin is not metabolized to progesterone and further to androgens and estrogens in mammalian organisms (Raju \& Mehta, 2009; Depypere \& Comhaire, 2014). It also does not bind to human estrogen or progesterone receptors in vitro (Depypere \& Comhaire, 2014). Recently, diosgenin was reported to not affect uterine weight and histomorphometric parameters, as well as expression of estrogen receptor $\alpha$ and progesterone receptor in the immature rat assay (Medigović et al., 2014), and estradiol level in both ovariectomized and non-ovariectomized adult rats (Chang et al., 2011). Consistently, diosgenin did not affect the serum estradiol level, and the mass of estrogen- dependent organs, the uterus and thymus, in the present study. It should be pointed out that the diosgenin effects on bone formation in the present study were different from those of estradiol $(0.2 \mathrm{mg} / \mathrm{kg}$ p.o.) which counteracted the increasing effect of estrogen-deficiency on compact bone formation in our previous report (Folwarczna et al., 2015). Moreover, estradiol did not affect the mechanical parameters of compact bone (Folwarczna et al., 2015). Taken together, the diosgenin effects on the skeletal system seemed to be not estrogenic.

However, diosgenin has been reported to exert its angiogenesis promoting effects on murine osteoblastic cells through estrogen receptor-related pathways (Yen et al., 2005), and to increase uterine weight in older rats after a longer treatment than that used in the present study (Zhang et al., 2014a). Also, Zhao et al. (2015) observed that diosgenin at a high dose $(90 \mathrm{mg} / \mathrm{kg}$ p.o.) increased serum estradiol level, which was decreased due the treatment with retinoic acid. A recent report by Sato et al. (2014) indicated that diosgenin increased levels of dehydroepiandrosterone and $5 \alpha$-dihydrotestosterone in the serum and muscle of male rats with streptozotocin-induced diabetes. It is possible that diosgenin may affect the skeletal system by acting through androgen receptors in bones. It is known that androgens induce periosteal growth, at least in male organisms (Manolagas, 2013). It was also proposed that there may be a specific receptor for dehydroepiandrosterone on osteoblasts, since dehydroepiandrosterone promoted proliferation and inhibited apoptosis of osteoblasts via pathways independent of androgen or estrogen receptors (Wang et al., 2007).

The slight, positive skeletal effects of diosgenin demonstrated in the present study confirmed that diosgenin or its derivates of better bioavailability may favorably affect bones, especially in disorders with decreased bone formation. It seems important that diosgenin effects were observed also in rats with normal bone turnover. However, there are some safety problems concerning the potential prophylactic use of diosgenin for osteoporosis. Although diosgenin probably did not affect estrogenic pathways in the present study, its possible androgenic effects should be taken into account, especially in women. Another problem is that saponins are known to induce hemolysis (Francis et al., 2002). However, diosgenin, a sapogenin, was reported to exert very low hemolytic activity, even at a high concentration of $100 \mu \mathrm{g} / \mathrm{ml}$ (Liu et al., 2013).

Diosgenin exerts its actions through various molecular targets (Shishodia \& Aggarwal, 2006; Raju \& Mehta, 2009; Jung et al., 2010; Alcantara et al., 2011; Kim et al., 2012; Patel et al., 2012). The resultant of the actions may be not favorable to bone. For example, it has been reported that anti-lipidemic effects of diosgenin are mediated by peroxisome proliferator-activated receptor $\gamma$ (PPAR $\gamma$ ) (Sangeetha et al., 2013). Deleterious effects of thiazolidinediones, PPAR $\gamma$ agonists, on the skeletal system were demonstrated (Lecka-Czernik, 2010). There is also a problem of the therapeutic window of diosgenin. Diosgenin exerted positive effects on osteoblastic cells in vitro at lower, but not at a high concentration, in which it became cytotoxic (Alcantara et al., 2011).

In conclusion, this study confirmed the previous reports on favorable skeletal effects of diosgenin in different experimental models and demonstrated in vivo that diosgenin may be one of sparse compounds increasing bone formation. 


\section{Acknowledgements}

The study was supported by grant No KNW-1076/P/2/0, Medical University of Silesia, Katowice, Poland.

\section{REFERENCES}

Alcantara EH, Shin MY, Sohn HY, Park YM, Kim T, Lim JH, Jeong HJ, Kwon ST, Kwun IS (2011) Diosgenin stimulates osteogenic activity by increasing bone matrix protein synthesis and bone-specific transcription factor Runx2 in osteoblastic MC3T3-E1 cells. J Nutr Biochem 22: 1055-1063. doi: 10.1016/j.jnutbio.2010.09.003.

Au AL, Kwok CC, Lee AT, Kwan YW, Lee MM, Zhang RZ, Ngai SM, Lee SM, He GW, Fung KP (2004) Activation of iberiotoxinsensitive, $\mathrm{Ca}^{2+}$-activated $\mathrm{K}^{+}$channels of porcine isolated left anterior descending coronary artery by diosgenin. Eur J Pharmacol 502: 123-133. doi: 10.1016/j.ejphar.2004.08.045.

Cayen MN, Dvornik D (1979) Effect of diosgenin on lipid metabolism in rats. J Lipid Res 20: 162-174. Available at: http://www.jlr.org/ content/20/2/162.long

Chang CC, Kuan TC, Hsieh YY, Ho YJ, Sun YL, Lin CS (2011) Effects of diosgenin on myometrial matrix metalloproteinase-2 and -9 activity and expression in ovariectomized rats. Int J Biol Sci 7: 837-847. doi:10.7150/ijbs.7.837.

Chen PS, Shih YW, Huang HC, Cheng HW (2011) Diosgenin, a steroidal saponin, inhibits migration and invasion of human prostate cancer PC-3 cells by reducing matrix metalloproteinases expression. PLoS One 6: e20164. doi: 10.1371/journal.pone.0020164.

Chiang SS, Chang SP, Pan TM (2011) Osteoprotective effect of Monascus-fermented dioscorea in ovariectomized rat model of postmenopausal osteoporosis. J Agric Food Chem 59: 9150-9157. doi: 10.1021 /if201640j.

Chiang SS, Pan TM (2013) Beneficial effects of phytoestrogens and their metabolites produced by intestinal microflora on bone health. Appl Microbiol Biotechnol 97: 1489-1500. doi: 10.1007/s00253-0124675-y.

Depypere HT, Comhaire FH (2014) Herbal preparations for the menopause: beyond isoflavones and black cohosh. Maturitas 77: 191-194. doi: 10.1016/j.maturitas.2013.11.001

Dias KL, Correia N de A, Pereira KK, Barbosa-Filho JM, Cavalcante KV, Araújo IG, Silva DF, Guedes DN, Neto Mdos A, Bendhack LM, Medeiros IA (2007) Mechanisms involved in the vasodilator effect induced by diosgenin in rat superior mesenteric artery. Eur J Pharmacol 574: 172-178. doi: 10.1016/j.ejphar.2007.07.017.

Folwarczna J, Janiec W, Barej M, Cegieła U, Pytlik M, KaczmarczykSedlak I (2004) Effects of nadroparin on bone histomorphometric parameters in rats. Pol J Pharmacol 56: 337-343. Available at: http:// www.rabbit.if-pan.krakow.pl/pjp/pdf/2004/3_337.pdf

Folwarczna J, Pytlik M, Zych M, Cegieła U, Kaczmarczyk-Sedlak I, Nowińska B, Śliwiński L (2013) Favorable effect of moderate dose caffeine on the skeletal system in ovariectomized rats. Mol Nutr Food Res 57: 1772-1784. doi: 10.1002/mnfr.201300123.

Folwarczna J, Pytlik M, Zych M, Cegieła U, Nowinska B, Kaczmarczyk-Sedlak I, Śliwinski L, Trzeciak H, Trzeciak HI (2015) Effects of caffeic and chlorogenic acids on the rat skeletal system. Eur Rev Med Pharmacol Sci 19: 682-693. Available at: http://www.europeanreview.org/article/8588.

Folwarczna J, Zych M, Nowińska B, Pytlik M (2014a) Effects of fenugreek (Trigonella foenum-graecum L.) seed on bone mechanical properties in rats. Eur Rev Med Pharmacol Sci 18: 1937-1947. Available at: http://www.europeanreview.org/article/7577.

Folwarczna J, Zych M, Nowińska B, Pytlik M, Janas A (2014b) Unfavorable effect of trigonelline, an alkaloid present in coffee and fenugreek, on bone mechanical properties in estrogen-deficient rats. Mol Nutr Food Res 58: 1457-1464. doi: 10.1002/mnfr.201300936.

Francis G, Kerem Z, Makkar HP, Becker K (2002) The biological action of saponins in animal systems: a review. Br J Nutr 88: 587-605. doi: $10.1079 / \mathrm{BJN} 2002725$.

Higdon K, Scott A, Tucci M, Benghuzzi H, Tsao A, Puckett A, Cason $Z$, Hughes J (2001) The use of estrogen, DHEA, and diosgenin in a sustained delivery setting as a novel treatment approach for osteoporosis in the ovariectomized adult rat model. Biomed Sci Instrum 37: 281-286.

Jung DH, Park HJ, Byun HE, Park YM, Kim TW, Kim BO, Um SH, Pyo S (2010) Diosgenin inhibits macrophage-derived inflammatory mediators through downregulation of CK2, JNK, NF-kappaB and AP-1 activation. Int Immunopharmacol 10: 1047-1054. doi: 10.1016/j. intimp.2010.06.004.

Kim DS, Jeon BK, Lee YE, Woo WH, Mun YJ (2012) Diosgenin induces apoptosis in HepG2 cells through generation of reactive oxygen species and mitochondrial pathway. Evid Based Complement Alternat Med 2012: 981675. doi: 10.1155/2012/981675.
Lecka-Czernik B (2010) Bone loss in diabetes: use of antidiabetic thiazolidinediones and secondary osteoporosis. Curr Osteoporos Rep 8: 178-184. doi: 10.1007/s11914-010-0027-y.

Liu Z, Gao W, Jing S, Zhang Y, Man S, Wang Y, Zhang J, Liu C (2013) Correlation among cytotoxicity, hemolytic activity and the composition of steroidal saponins from Paris L. J Ethnopharmacol 149: 422-430. doi: 10.1016/j.jep.2013.06.033.

Manda VK, Avula B, Ali Z, Wong YH, Smillie TJ, Khan IA, Khan SI (2013) Characterization of in vitro ADME properties of diosgenin and dioscin from Dioscorea villosa. Planta Med 79: 1421-1428. doi: 10.1055/s-0033-1350699.

Manolagas SC, O’Brien CA, Almeida M (2013) The role of estrogen and androgen receptors in bone health and disease. Nat Rev Endocrinol 9: 699-712. doi: 10.1038/nrendo.2013.179.

Medigović I, Ristić N, Živanović J, Šošić-Jurjević B, Filipović B, Milošević V, Nestorović N (2014) Diosgenin does not express estrogenic activity: a uterotrophic assay. Can J Physiol Pharmacol 92: 292-298. doi: 10.1139/cjpp-2013-0419.

Okawara M, Tokudome Y, Todo H, Sugibayashi K, Hashimoto F (2013) Enhancement of diosgenin distribution in the skin by cyclodextrin complexation following oral administration. Biol. Pharm. Bull. 36: 36-40. doi: 10.1248/bpb.b12-00467.

Patel K, Gadewar M, Tahilyani V, Patel DK (2012) A review on pharmacological and analytical aspects of diosgenin: a concise report. Nat Prod Bioprospect 2: 46-52. doi: 10.1007/s13659-012-0014-3.

Qu X, Zhai Z, Liu X, Li H, Ouyang Z, Wu C, Liu G, Fan Q, Tang T, Qin A, Dai K (2014) Dioscin inhibits osteoclast differentiation and bone resorption though down-regulating the Akt signaling cascades. Biochem. Biophys Res Commun 443: 658-665. doi: 10.1016/j. bbrc.2013.12.029.

Rachner TD, Khosla S, Hofbauer LC (2011) Osteoporosis: now and the future. Lancet 377: 1276-1287. doi: 10.1016/S01406736(10)62349-5.

Rajput S, Mandal M (2012) Antitumor promoting potential of selected phytochemicals derived from spices: a review. Eur J Cancer Prev 21: 205-215. doi: 10.1097/CEJ.0b013e32834a7f0c.

Raju J, Mehta R (2009) Cancer chemopreventive and therapeutic effects of diosgenin, a food saponin. Nutr Cancer 61: 27-35. doi: $10.1080 / 01635580802357352$.

Sangeetha MK, ShriShri Mal N, Atmaja K, Sali VK, Vasanthi HR (2013) PPAR's and diosgenin a chemico biological insight in NIDDM. Chem Biol Interact 206: 403-410. doi: 10.1016/j.cbi.2013.08.014.

Sato K, Fujita S, Iemitsu M (2014) Acute administration of diosgenin or dioscorea improves hyperglycemia with increases muscular steroidogenesis in STZ-induced type 1 diabetic rats. I Steroid Biochem Mol Biol 143: 152-159. doi: 10.1016/i.jsbmb.2014.02.020.

Sausbier U, Dullin C, Missbach-Guentner J, Kabagema C, Flockerzie K, Kuscher GM, Stuehmer W, Neuhuber W, Ruth P, Alves F, Sausbier M (2011) Osteopenia due to enhanced cathepsin $K$ release by BK channel ablation in osteoclasts. PLoS One 6: e21168. doi: 10.1371/journal.pone.0021168.

Scott A, Higdon K, Tucci M, Benghuzzi H, Puckett A, Tsao A, Cason Z, Hughes J (2001) The prevention of osteoporotic progression by means of steroid loaded TCPL drug delivery systems. Biomed Sci Instrum 37: 13-18.

Shishodia S, Aggarwal BB (2006) Diosgenin inhibits osteoclastogenesis, invasion, and proliferation through the downregulation of Akt, IkappaB kinase activation and NF-kappaB-regulated gene expression. Oncogene 25: 1463-1473. doi:10.1038/sj.onc.1209194.

Stürmer EK, Seidlová-Wuttke D, Sehmisch S, Rack T, Wille J, Frosch KH, Wuttke W, Stürmer KM (2006) Standardized bending and breaking test for the normal and osteoporotic metaphyseal tibias of the rat: effect of estradiol, testosterone, and raloxifene. J Bone Miner Res 21: 89-96. doi: 10.1359/JBMR.050913.

Tella SH, Gallagher JC (2014) Prevention and treatment of postmenopausal osteoporosis. I Steroid Biochem Mol Biol 142: 155-170. doi: 10.1016/j.jsbmb.2013.09.008.

Tikhonova MA, Ting CH, Kolosova NG, Hsu CY, Chen JH, Huang CW, Tseng GT, Hung CS, Kao PF, Amstislavskaya TG, Ho YJ (2015) Improving bone microarchitecture in aging with diosgenin treatment: A study in senescence-accelerated OXYS rats. Chin J Physiol 58: 322-331. doi: 10.4077/CJP.2015.BAD325.

Turner CH, Burr DB (1993) Basic biomechanical measurements of bone: a tutorial. Bone 14: 595-608. doi:10.1016/8756-3282(93)90081K.

Uemura T, Hirai S, Mizoguchi N, Goto T, Lee JY, Taketani K, Nakano Y, Shono J, Hoshino S, Tsuge N, Narukami T, Takahashi N, Kawada T (2010) Diosgenin present in fenugreek improves glucose metabolism by promoting adipocyte differentiation and inhibiting inflammation in adipose tissues. Mol Nutr Food Res 54: 1596-1608. doi: $10.1002 / \mathrm{mnfr} .200900609$.

Wang L, Wang YD, Wang WJ, Zhu Y, Li DJ (2007) Dehydroepiandrosterone improves murine osteoblast growth and bone tissue morphometry via mitogen-activated protein kinase signaling pathway independent of either androgen receptor or estrogen receptor. $J$ Mol Endocrinol 38: 467-479. doi: 10.1677/jme.1.02173. 
Yen ML, Su JL, Chien CL, Tseng KW, Yang CY, Chen WF, Chang CC, Kuo ML (2005) Diosgenin induces hypoxia-inducible factor-1 activation and angiogenesis through estrogen receptor-related phosphatidylinositol 3-kinase/Akt and p38 mitogen-activated protein kinase pathways in osteoblasts. Mol Pharmacol 68: 1061-1073. doi: 10.1124/mol.104.010082.

Yin J, Han N, Liu Z, Song S, Kadota S (2010) The in vitro antiosteoporotic activity of some glycosides in Dioscorea spongiosa. Biol Pharm Bull 33: 316-320. doi: 10.1248/bpb.33.316.

Yin J, Tezuka Y, Kouda K, Le Tran Q, Miyahara T, Chen Y, Kadota $S$ (2004) In vivo antiosteoporotic activity of a fraction of Dioscored spongiosa and its constituent, 22-O-methylprotodioscin. Planta Med 70: 220-226. doi: $10.1055 / \mathrm{s}-2004-815538$.
Zhang Z, Song C, Fu X, Liu M, Li Y, Pan J, Liu H, Wang S, Xiang L, Xiao GG, Ju D (2014a) High-dose diosgenin reduces bone loss in ovariectomized rats via attenuation of the RANKL/OPG ratio. Int J Mol Sci 15: 17130-17147. doi: 10.3390/ijms150917130.

Zhang Z, Xiang L, Bai D, Fu X, Wang W, Li Y, Liu H, Pan J, Li Y, Xiao GG, Ju D (2014b) Treatment with Rhizoma Dioscoreae extract has protective effect on osteopenia in ovariectomized rats. Scientific World Journal 2014: 645975. doi: 10.1155/2014/645975.

Zhao S, Niu F, Xu CY, Liu Y, Ye L, Bi GB, Chen L, Tian G, Nie TH (2015) Diosgenin prevents bone loss on retinoic acid-induced osteoporosis in rats. Ir J Med Sci [Epub ahead of print] doi: 10.1007/ s11845-015-1309-2. 